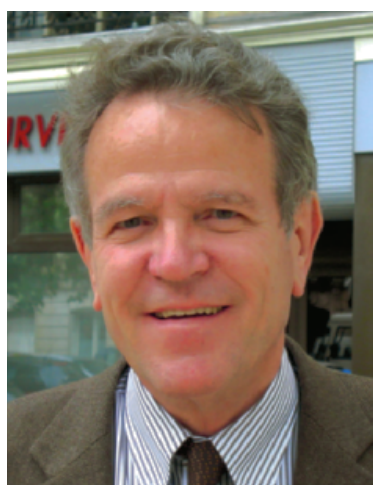

D. Gastambide

\section{Endoscopic spine surgery: what does it mean? What is the future?}

On the behalf of Christian Mazel, I warmly welcome the opportunity to present several endoscopic surgery techniques in the ArgoSpine Journal for the first time. At first, the techniques described in this issue must be distinguished from those using tubes of more than $16 \mathrm{~mm}$ diameter, or an endoscopic tube as in the Destandau technique. As I only use endoscopes of less than $7 \mathrm{~mm}$ of external diameter with an internal working channel from $3.6 \mathrm{~mm}$ to $4.1 \mathrm{~mm}$, I prefer to follow Ruetten's example and rather use the term "full endoscopy" when defining this technique. The term was first introduced in the medical literature by this German physician and had never been used before in the English-speaking medical world. Although I tried to translate it, I could not find an appropriate equivalent.

You will find a section about the elementary technique of transforaminal discectomy detailed step by step where we present the results with a follow-up of at least two years. At the conclusion of this section, we will compare the results obtained with the "full endoscopic" and non-"full-endoscopic" techniques through a 16 to $24 \mathrm{~mm}$ tube, and we will discuss the advantages and drawbacks of each option.

The second article is on full endoscopic interlaminar discectomy (by Gun Choi), a very special technique where being savvy is as important as the quality of the optics and of the specific tools. A third chapter will be about cervical discectomy and a fourth about thoracic discectomy (by Sang-Ho Lee and Ho-Yeong Kang). To complete this presentation about full endoscopic techniques, the fifth contribution will be on Pe-TLIF (Percutaneous Transforaminal Interbody Fusion).

All these techniques have been made possible by the use of endoscopes with working channels, allowing surgeons to operate under direct vision and to see their forceps from $2.5 \mathrm{~mm}$ to $3.5 \mathrm{~mm}$ of diameter for transforaminal approaches and $4.0 \mathrm{~mm}$ for interlaminar approaches or to control all coagulators (radiofrequency or Holmium-YAG laser).

We dearly hope that the interest in minimally invasive approaches will encourage the reader to evaluate each of the procedures described in the following chapters and prompt him/her to consider learning these techniques. • 